\title{
Duodenal Web Unmasked by Ingested Foreign Body
}

Lee Young ${ }^{*}$, Nick Mellsop, Kong Au Yong, Jitoko Cama and Duncan Lamont

Department of Ultrasound, Radiology, Waikato Hospital, Pembroke Street, Hamilton, New Zealand

*Corresponding author: Lee Young, Department of Ultrasound, Radiology, Waikato Hospital, Pembroke Street, Hamilton, New Zealand, Tel: +647839 8899; E-mail: Lee.Young@waikatodhb.health.nz

Received Date: Feb 01, 2018; Accepted Date: Feb 20, 2018; Published Date: Feb 28, 2018

Copyright: (C) 2017 Young L, et al. This is an open-access article distributed under the terms of the Creative Commons Attribution License, which permits unrestricted use, distribution, and reproduction in any medium, provided the original author and source are credited.

\begin{abstract}
This case report demonstrates a common presentation and classical radiological findings of a duodenal web with a small orifice, but which was unmasked by ingestion of a foreign body, causing acute complete duodenal obstruction.
\end{abstract}

Keywords: Duodenal atresia; Duodenal web; Failure to thrive; Congenital duodenal anomaly; Bilious vomiting

\section{Introduction}

Duodenal web is a rare congenital anomaly related to recanalization failure and incomplete vacuolization during early embryologic foregut development resulting in subsequent partial or complete obstruction [1]. This can be detected during neonatal period but diagnosis can be delayed depending on the degree of stenosis and exacerbation factors.

Occurrence at the second part of the duodenum is most frequently seen; representing $85-90 \%$ of cases [2].

Common presentations include upper abdominal pain, distension and post-prandial vomiting in a background of failure to thrive [3].

Abdominal radiographs and upper GI contrast studies are valuable diagnostic tools [4], demonstrating classical, radiological signs including 'double bubble' [5] and 'wind sock signs' [6].

\section{Case Report}

A 16 month old female with known history of recurrent vomiting from the 7 months was admitted to us. This vomiting occurred twothree times per night; characteristically occurred 30-60 minutes post feed. The child had had required two prior hospital admissions for correction of associated dehydration and metabolic disturbances.

On this occasion, she re-presented with bilious vomiting, upper abdominal distension and electrolyte imbalance, she was on the 50th percentile for weight.

Abdominal $\mathrm{x}$-ray showed a $14 \mathrm{~mm}$ round radio-opaque foreign body within the stomach with associated stomach and proximal duodenal distension (Figure 1).

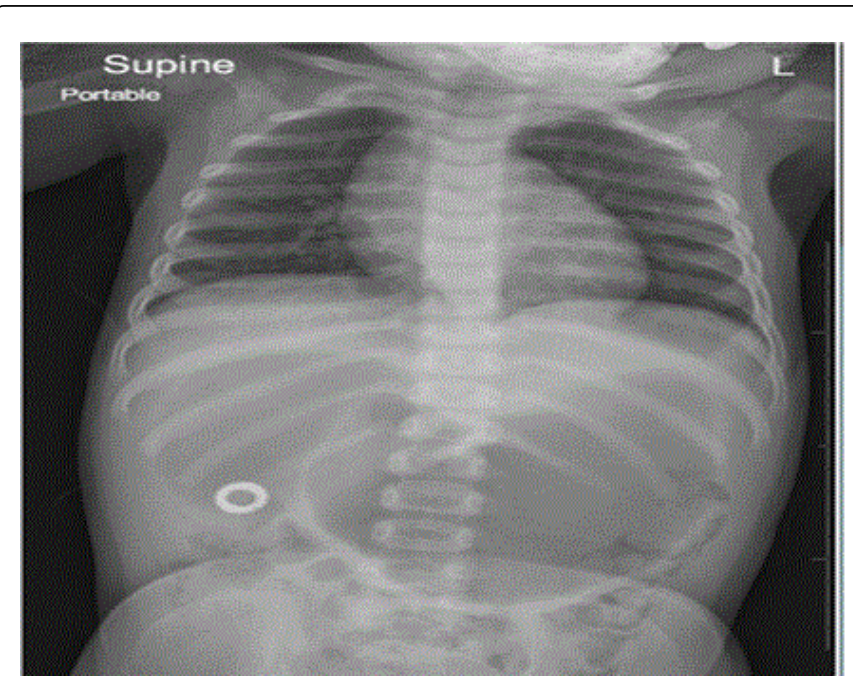

Figure 1: The 'double bubble' sign.

The UGI contrast study showed that contrast medium failed to pass the foreign body which was in the 2 nd part of the duodenum (Figures 2 and 3 ).

Appearances were those of complete duodenal obstruction. In the absence of further oral contrast transit, mal-rotation and volvulus cannot be excluded.

Gastro-duodenoscopy confirmed the presence of a foreign body and a duodenal web. There was a pin-hole perforation through the duodenal web (Figure 4). 
Citation: Young L, Mellsop N, Yong KA, Cama J, Lamont D (2018) Duodenal Web Unmasked by Ingested Foreign Body. Med Rep Case Stud 3: 149. doi:10.4172/2572-5130.1000149

Page 2 of 3

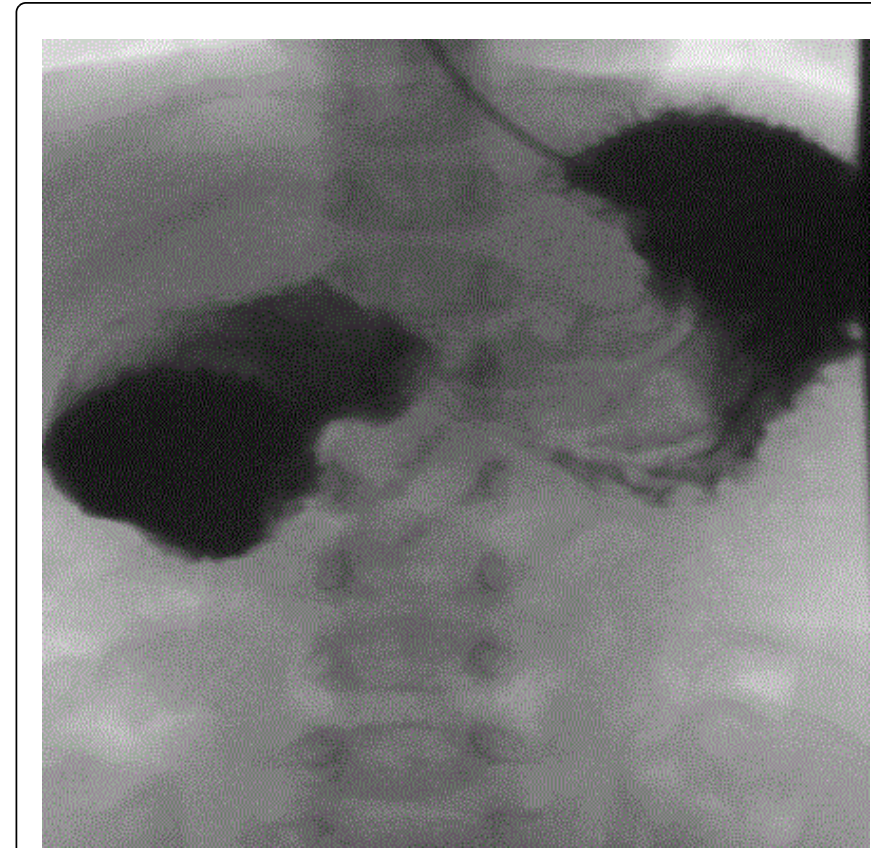

Figure 2: Contrast failing to pass the site of foreign body.

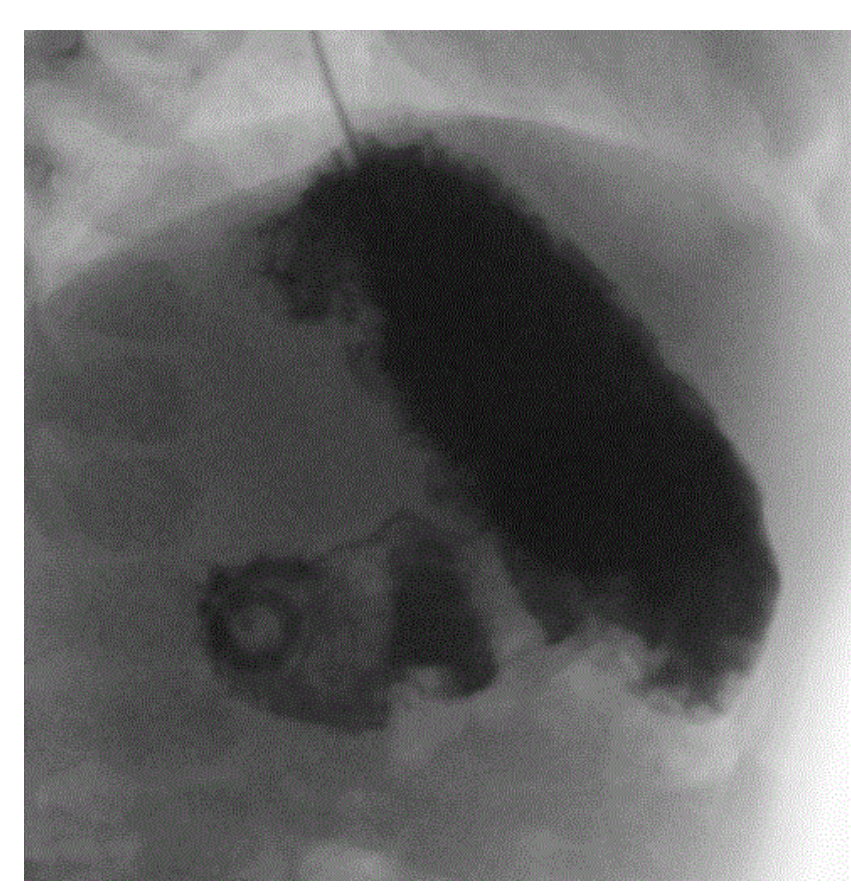

Figure 3: Contrast failing to pass the site of foreign body.

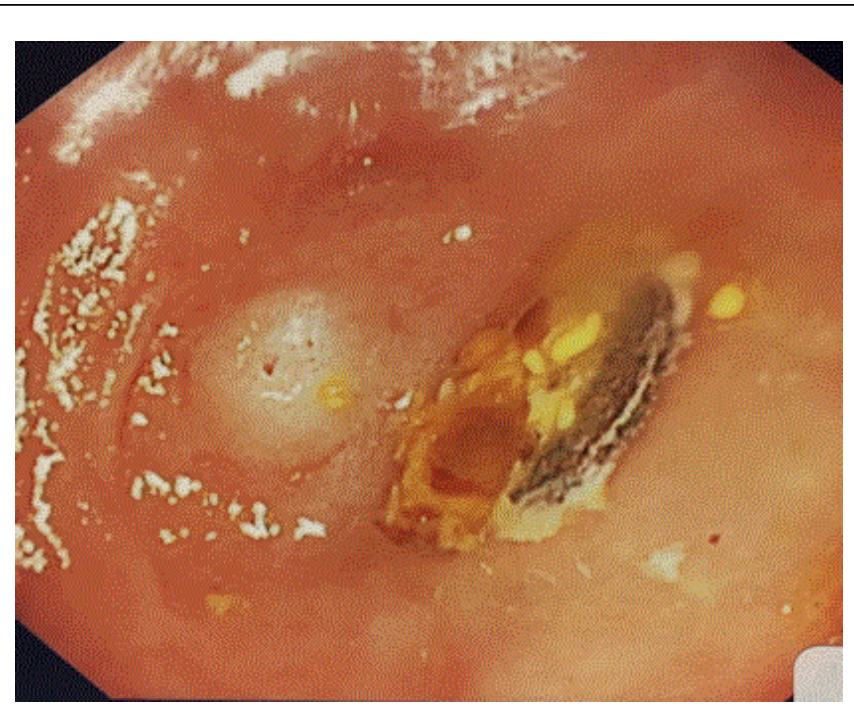

Figure 4: Endoscopic views of the duodenal web and lodged foreign body.

Laparotomy was performed (Figures 5 and 6), and the web was excised, the surgeon was careful to avoid ampulla injury, and a transverse closure was done to widen the lumen of the 2nd part of the duodenum.

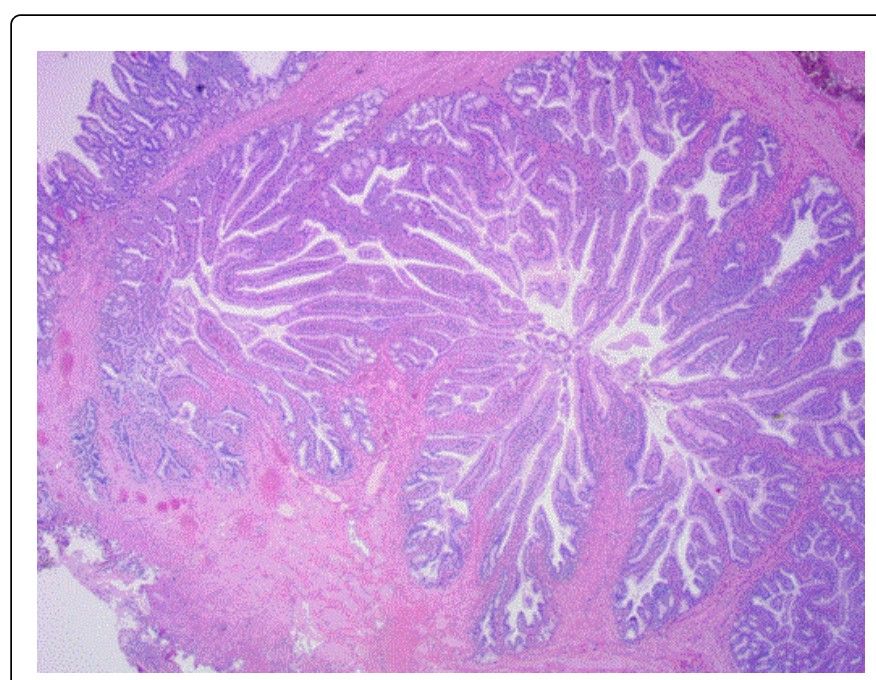

Figure 5: Haematoxylin and Eosin stain, X20. A narrow lumen within the duodenum is demonstrated. No inflammation or malignancy is identified. 
Citation: Young L, Mellsop N, Yong KA, Cama J, Lamont D (2018) Duodenal Web Unmasked by Ingested Foreign Body. Med Rep Case Stud 3: 149. doi:10.4172/2572-5130.1000149

Page 3 of 3

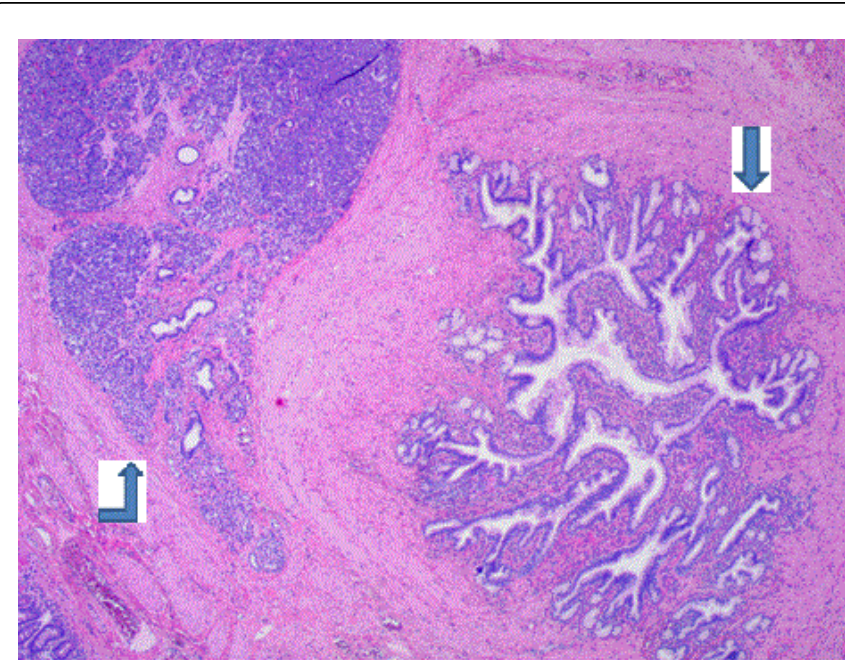

Figure 6: Haematoxylin and Eosin stain, X40. This slide demonstrates the duodenal web to the right and ectopic pancreatic tissue to the left.

\section{Conclusion}

This case report demonstrates a common presentation and classical radiological findings of a duodenal web with a small orifice, but which was unmasked by ingestion of a foreign body, causing acute complete duodenal obstruction.

\section{References}

1. Boyden EA, Cope J, Bill AH (1967) Anatomy and embryology of congenital intrinsic obstruction of the duodenum. Am J Surg 114: 190-202.

2. Mahajan SK, Kashyap R, Chandel UK, Mokta J, Minhas SS (2004) Duodenal diverticulum: Review of Literature. Indian J Surg 66: 1450-1453.

3. Melek M, Edirne YE (2008) Two cases of duodenal obstruction due to a congenital web: World J Gastroenterol 14: 1305-1307.

4. Berrocal T, Torres I, Gutiérrez J, Prieto C, del Hoyo ML, et al. (1999) Congenital anomalies of the upper gastrointestinal tract. Radiographics 19: 855-872.

5. Traubici J (2001) The Double Bubble Sign. Radiology 220: 463-464.

6. Materne R (2001) The duodenal wind sock sign. Radiology 218: 749-750. 